\title{
Neoadjuvant TP (Cisplatin-Docetaxel) for patients unfit to TPF (Cisplatin-Docetaxel-5FU) in locally advanced head and neck squamous cell cancer (LAHNSCC): an exploratory study on 14 patients
}

Jérôme Fayette* ${ }^{* 1}$,Emilie Lavergne ${ }^{2}$, Antoine Ramade ${ }^{3}$, Philippe Zrounba ${ }^{4}$, Didier Girodet ${ }^{4}$, Eve-Marie Neidhardt ${ }^{1}$, Sylvie Chabaud ${ }^{2}$, Julien Péron $^{5}$, Marc Poupart ${ }^{6}$, and Philippe Céruse ${ }^{3,7}$

${ }^{1}$ Department of Medicine, Léon Bérard Center, University of Lyon, Lyon, France

${ }^{2}$ Department of Biostatistics, Léon Bérard Center, University of Lyon, Lyon, France

${ }^{3}$ Department of Surgery, Edouard Herriot Hospital, University of Lyon, Lyon, France

${ }^{4}$ Department of Surgery, Léon Bérard Center, University of Lyon, Lyon, France

${ }^{5}$ Department of Medicine, Lyon Sud Hospital Center, University of Lyon, Pierre-Bénite, France

${ }^{6}$ Department of Surgery, Croix-Rousse Hospital, University of Lyon, Lyon, France

${ }^{7}$ Department of Surgery, Lyon Sud Hospital Center, University of Lyon, Pierre-Bénite, France

\begin{abstract}
Background: TPF is standard induction chemotherapy for locoregionally advanced head and neck squamous cell carcinoma (LAHNSCC) but reserved to patients younger than 70 years, with good functional status and without comorbidities. We studied in an exploratory cohort of patients unfit to TPF the impact of $5 \mathrm{FU}$ suppression in terms of safety and efficacy.

Methods: Between December 2005 and November 2009, 14 patients received 3 cycles of Cisplatin and Docetaxel every 3 weeks. Outcomes were collected including response rate, overall survival, and progression-free survival ant toxicity.

Results: Median age at diagnosis was 59 years [42-75]. Patients received TP rather than TPF because of denutrition, history of cardiovascular disease or advanced age. Tumor localizations were: oral cavity (7\%), oropharynx (29\%), hypopharynx (43\%), larynx (7\%) and rhinopharynx (14\%). Eight (57\%) were inoperable.

Three patients had only one cycle ( 1 toxicity and 2 because radiochemotherapy was planned rapidly), 1 two cycles (grade 3 mucositis and progression) and 3 four cycles. Three patients required secondary hospitalization after the first cycle ( 2 for febrile neutropenia and 1 for grade 4 colitis). No febrile neutropenia neither secondary hospitalization was observed later. Five patients (36\%) had CR and $7(50 \%)$ PR for an ORR of 86\%. We observed 1 PD and 1 SD (the patient benefited from radical surgery and was still alive). All patients, except one, were irradiated without temporary interruption or toxic death. After a median follow-up of 72 months (95\% CI [15-35]), 4 patients progressed (1 during induction) and 3 died of not-cancer related cause. The median OS was 54 months ( $95 \%$ CI; 41 - not reached).
\end{abstract}

Conclusions: These preliminary and encouraging results raise the interest for a future comparison between TP and TPF regimen in patients with LAHNSCC.

\begin{abstract}
Abbreviations: TP: Cisplatin-Docetaxel, TPF: Cisplatin-Docetaxel5FU, 5FU: fluorouracile, LAHNSCC: locally advanced head and neck squamous cell cancer, HNSCC: head and neck squamous cell cancer, CR: complete response, PR: partial response, PD: progressive disease, ORR: objective response rate, OS: overall survival, PFS: progression free survival, PF: cisplatin 5FU, G-CSF: Granulocyte colony-stimulating factor, RECIST: Response Evaluation Criteria in Solid Tumors, HR: hazard ratio
\end{abstract}

\section{Introduction}

Around 120,000 patients in Western countries have head and neck squamous cell carcinoma (HNSCC) [1], with approximately two-thirds of cases being locoregionally advanced (LAHNSCC) [2]. Despite multimodality therapy combining surgery, radiotherapy and chemotherapy, $25-50 \%$ of patients experience a relapse.
For LAHNSCC, induction chemotherapy by a combination of taxotere, cisplatin and 5-Fluorouracil (TPF) followed by radiotherapy was validated for organ preservation [3] but did not demonstrated benefit in terms of overall survival in three large III studies [4-6]. But the methodology of these studies has been criticized and TPF remains largely used in routine practice since it demonstrated clear increase of overall survival compared to induction by cisplatin-5FU (PF) $[7,8]$.

Correspondence to: Jérôme Fayette, Department of Medicine, Léon Bérard Center, University of Lyon, Lyon, France; Tel: + 334787851 03; Fax: + 33478 7827 16; E-mail: jerome.fayette@lyon.unicancer.fr

Key words: TPF, head and neck cancer, induction, chemoradiation, cisplatin, docetaxel

Received: June 09, 2016; Accepted: June 20, 2016; Published: June 24, 2016 
TPF has high toxicity in routine practice [9] and its usage is restricted to patients with good functional status, younger than 70 years, without comorbidities including important weight loss. So, a large part of patients with LAHNSCC are unfit for TPF and often for surgery or radiotherapy. For this type of patients we proposed induction chemotherapy without 5FU with the combination of Cisplatin and Docetaxel (TP). After decision of multidisciplinary team, we proposed to 14 patients unfit for TPF to receive induction chemotherapy by TP because they were unfit (or refused) for surgery or immediate radiotherapy too. The aim of this exploratory study was to determine if this schedule is safe and efficient in induction.

\section{Patients and methods}

\section{Patients and treatment}

Between December 2005 and November 2009, patients with LAHNSCC who were unfit (or refused) for surgery or immediate radiotherapy and who were considered unfit for TPF induction were treated after decision of a multidisciplinary team with induction TP (cisplatin and docetaxel, each at $75 \mathrm{mg} / \mathrm{m}^{2}$ ), both at day 1 every 3 weeks for 3 to 4 cycles in our institution. All patients received adequate antiemetic prophylaxis and prednisolone $(50 \mathrm{mg}$, orally, six times starting on the morning before chemotherapy) to prevent hypersensitivity reactions and reduce docetaxel-related skin toxicity and fluid retention. Granulocyte colony-stimulating factor (G-CSF) was administered for primary prophylaxis, starting on day 4 for five days. No antibiotic was administered prophylactically.

After TP, and according to multidisciplinary decisions, patients underwent surgery (neck dissection and/or tumor surgery) followed by radiotherapy within three to seven weeks of completion of chemotherapy or surgery. Radiation was delivered over a sevenweek period using conventional fractionation (total dose of 66 to 70 Gy). Radiotherapy was administered alone if the patient was judged unsuitable for potentiation or was potentiated with $\mathrm{q} 3 \mathrm{w}$ cisplatin $(100$ $\mathrm{mg} / \mathrm{m}^{2}$ on days 1,22 and 43 ) or q1w cisplatin (35 $\mathrm{mg} / \mathrm{m}^{2}$ weekly) or cetuximab $\left(400 \mathrm{mg} / \mathrm{m}^{2}\right.$ one week before radiotherapy, then $250 \mathrm{mg} /$ $\mathrm{m}^{2}$ weekly).

Patient data were collected in accordance with CNIL rules (the French authority for protection of patient data) and kept anonymous.

\section{Assessment}

Tumor responses were evaluated by clinical exam and CT-scan according to RECIST 1.0 criteria. Patients had cervical and thoracic CTs before treatment and after two cycles of TP. Patients with hypopharyngeal or laryngeal cancer underwent another panendoscopy. The response rate was the proportion of patients who achieved complete or partial response out of the total number of patients who received at least one cycle of TP. Overall survival (OS) was defined as the time from the date of diagnosis to the date of death or to the date of the last follow-up for surviving patients (censored cases). Progression-free survival (PFS) was defined as the time from the date of diagnosis to the date of disease progression or death, or to the date of the last follow-up for patients alive without progression at last contact. Survival estimates were calculated using the Kaplan-Meier method.

\section{Results}

\section{Patient characteristics}

Between December 2005 and November 2009, 14 patients with histologically confirmed LAHNSCC were treated with TP. The median age was 59 years at diagnosis and 9/14 patients had stage IV disease and $8 / 14$ were not operable (Table 1 ). There were three reasons for choosing TP instead of TPF for induction chemotherapy: weight loss $>10 \%$, age $>70$ years and cardiovascular disease that was a contra-indication for the use of $5 \mathrm{FU}$.

\section{TPF delivery and safety}

A total of 38 cycles were delivered. Only two patients stopped treatment due to toxicity with 3 secondary hospitalizations after the first cycle: 2 for febrile neutropenia and 1 for colitis. For the following cycles, neither toxicity nor secondary hospitalization was observed. Two patients received only 1 cycle because chemotherapy was started due to delay for onset of radiotherapy (Table 2). No death related to toxicity of the TP combination was observed.

\section{Efficacy of TP and subsequent treatment}

All patients were evaluated. The overall response rate according to the RECIST intent to treat criteria was high at $86 \%$, of which $36 \%$ (5 patients) were complete and 50\% (7 patients) partial responses (Table $3)$. One patient (7\%) had stable disease and one (7\%) progressed on treatment. After chemotherapy, one patient had radical surgery (he was stable on chemotherapy) and 4 had neck dissection. Thirteen patients

Table 1. Patient characteristics at onset of TP.

\begin{tabular}{|l|c|}
\hline & Number of patients (14) \\
\hline Median age, years [range] & $59[42-75]$ \\
\hline Sex & 1 \\
Female & 13 \\
Male & \\
\hline Tumor site at initial diagnosis & 1 \\
Oral cavity & 4 \\
Oropharynx & 6 \\
Hypopharynx & 1 \\
Larynx & 2 \\
Nasopharynx & \\
\hline Tumor stage at initial diagnosis & 1 \\
II & 4 \\
III & 7 \\
Iva & 2 \\
IVb & \\
\hline Operable patient & \\
Yes & 6 \\
No & 8 \\
\hline PS & \\
0 & 4 \\
1 & 10 \\
\hline
\end{tabular}

Table 2. Delivery and toxicity of TP.

\begin{tabular}{|c|c|c|}
\hline & $\mathbf{N}$ & Comments \\
\hline \multicolumn{3}{|c|}{ Number of cycles received } \\
\hline 1 cycle & 3 & $\begin{array}{l}2 \text { because TP wasproposed due to delay for } \\
\text { radiotherapy } \\
1 \text { due to toxicity }\end{array}$ \\
\hline 2 cycles & 1 & Progression and toxicity \\
\hline 3 cycles & 7 & \\
\hline 4 cycles & 3 & \\
\hline \multicolumn{3}{|c|}{ Secondary hospitalization } \\
\hline After cycle 1 & 3 & 2 febrile neutropenia, 1 grade 4 colitis \\
\hline After cycles 2,3 or 4 & 0 & \\
\hline \multicolumn{3}{|l|}{ Febrile neutropenia } \\
\hline After cycle 1 & 2 & \\
\hline After cycles 2,3 or 4 & 0 & \\
\hline
\end{tabular}


Fayette J (2016) Neoadjuvant TP (Cisplatin-Docetaxel) for patients unfit to TPF (Cisplatin-Docetaxel-5FU) in locally advanced head and neck squamous cell cancer (LAHNSCC): an exploratory study on 14 patients

Table 3. Best response to TP.

\begin{tabular}{|c|c|c|}
\hline Best response to $\mathrm{TP}$ & $\mathbf{N}$ & $\%$ \\
\hline Overall response rate & 12 & 86 \\
\hline Complete response & 5 & 36 \\
\hline Partial response & 7 & 50 \\
\hline Stable disease & 1 & 7 \\
\hline Progressive disease & 1 & 7 \\
\hline
\end{tabular}

(93\%) were irradiated, 3 (21\%) with exclusive radiotherapy, 2 (14\%) with potentiation by cetuximab, 4 (29\%) with potentiation by weekly cisplatin (but 2 patients did not received the 7 cycles planned) and 4 (29\%) with potentiation by q3w cisplatin (but 2 patients received only 2 cycles). One patient progressed during radiotherapy (he progressed during TP too).

\section{Survival}

After a median follow-up of 72 months (range 59 monthsunreached), 4 (29\%) patients relapsed or progressed, mostly at the loco regional level, and died of their disease. Three other patients died of not-cancer related cause. Finally 7 patients were alive free of disease after a minimal follow-up of 60 months. The median progression-free survival (PFS) was 54 months (95\% CI: 26 months-unreached) (Figure $1 \mathrm{~A})$ and the median overall survival (OS) was 54 months too $(95 \%$ CI: 41 months-unreached) (Figure 1B). The median cancer-specific survival was not reached (95\% CI: 41 months-unreached).

\section{Discussion}

This exploratory study demonstrates the effectiveness and tolerability of induction chemotherapy using TP for LAHNSCC for patients unfit to TPF. The response rate of $86 \%$ is comparable to the 68-80\% response rate observed with TPF in randomized trials and in routine practice (7-10). On 14 patients, only 4 died of their disease and the median OS was 54 months that is worthy for patients with LAHNSCC. Furthermore, these patients unfit for TPF had probably a lower life expectancy than patients fit for TPF.

Interestingly, this scheme was tolerable since we did not observe toxic death; and only $3 / 14$ patients had secondary hospitalization and early treatment discontinuation related to toxicity was necessary for only 2/14 patients. With G-CSF support, 2/14 (14\%) patients had febrile neutropenia. The frequency of febrile neutropenia was then comparable to the level of $12 \%$ reported in our previous study in routine practice of TPF [9]. Since many patients with LAHNSCC are not eligible for TPF, this scheme could increase the number of patients eligible for induction chemotherapy.

The place of induction chemotherapy is still debated. The first studies with the PF (cisplatin-5FU scheme) did not demonstrate significant rates of survival or larynx preservation between $\mathrm{PF}$ followed by radiotherapy and exclusive chemoradiation $[3,11]$. The results at 5 and 10 years of the RTOG 91-11 study found that chemoradiotherapy improves laryngeal preservation $(83.6 \%$ at 5 years and $81.7 \%$ at 10 years) compared with induction chemotherapy followed radiotherapy (70.8\% and 67.5\%) (12). But for composite endpoint of survival without laryngectomy (which was the main objective ) there is no difference with $47 \%$ and $23.5 \%$ at 5 and 10 years for the concomitant scheme against $44.1 \%$ and $28.9 \%$ for the induction $(\mathrm{HR}=1.05,95 \%$ CI 0.83 to $1.34, \mathrm{p}=0.68$ ). For overall survival curves separate for induction chemotherapy from 4.5 years. However, in 10 years, the difference does not quite reach statistical significance with a survival rate of $27.5 \%$ for concomitant against $38.8 \%$ for induction $(\mathrm{HR}=1.25,95 \%$ CI 0.98 -
$1.61, \mathrm{p}=0.08)$. It should be noted that the median follow-up was 10.8 years for surviving patients while the trial included patients between 1992 and 2000. Subsequent data are not shown and cannot rule out that if the analysis had was made 10 years after the end of the trial and not 10 years (or barely) after inclusion survival data could be significant for induction with PF.

Induction by TPF demonstrated superiority to PF in terms of overall survival and laryngeal preservation and become the standard treatment when induction is chosen $[7,8,10,13]$.

Given the superiority of TPF induction regimen compared to $\mathrm{PF}$ and in the absence of survival difference in comparative studies between exclusive chemoradiation and PF induction followed by radiotherapy, the benefit of induction chemotherapy over concomitant chemoradiotherapy for organ preservation and for inoperable tumors is a matter of ongoing debate. Three phase III studies were designed
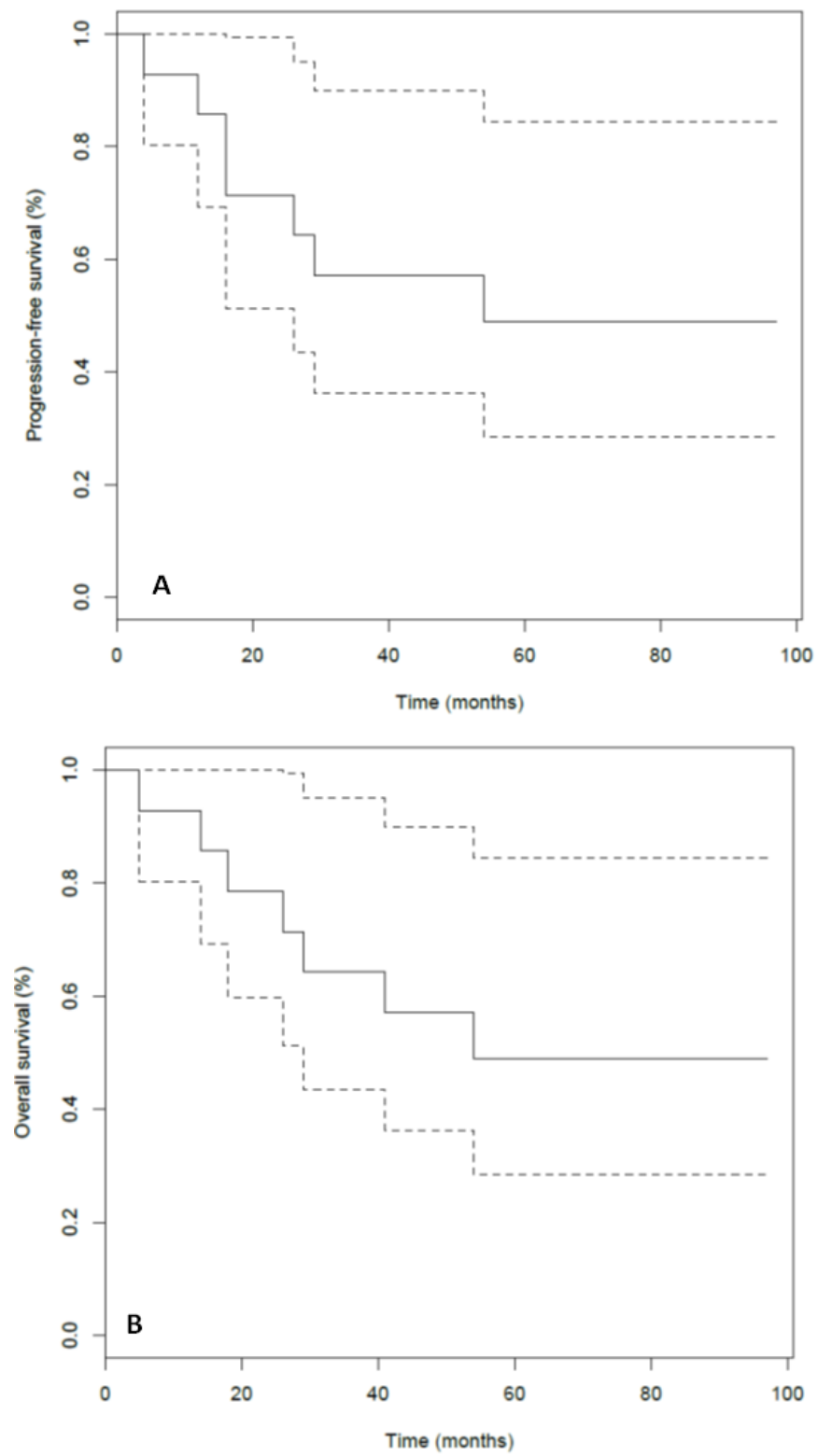

Figure 1. Progression-free survival (A) and overall survival (B) with a median follow-up of 72 months.

Plain lines: survival. Dashed lines: terminals of $95 \% \mathrm{CI}$. 
to answer to this question but failed to conclude essentially due to methodological problems. In the first trial the per-protocol analysis showed superiority of induction followed by chemoradiation but did not reach a statistical significance in intent to treat analysis due to high levels of toxicity [6]. In two others, the inclusions were lower than expected and planned number of included patients was not reached: finally, no statistical benefit to induction chemotherapy could be shown in those trials $[4,5]$. The lack of significant difference does not allow concluding to equivalence because the statistical power was insufficient. So today there is no indisputable superiority of argument either approaches. In practice, patients unfit to TPF are unfit to chemoradiation with cisplatin at $100 \mathrm{mg} / \mathrm{m}^{2}$ every 3 weeks, and for these patients induction with TP could be a possible therapeutic option.

Since the demonstration of the efficacy of cetuximab concomitant to radiotherapy for LAHNSCC [14] or in combination with PF in first line of recurrent/metastatic disease [15], some studies explored the addition of cetuximab to TPF. Results are promising but toxicity is not negligible [16]. In recurrent/metastatic disease the combination of TP and cetuximab demonstrated promising result with an OS that can reach 14 months in a phase II study [17]. So our results support the study of the combination of cisplatine, docetaxel and cetuximab as induction chemotherapy for LAHNSCC.

\section{Conclusion}

Our exploratory study suggests that TP could be as efficient as TPF for patients with LAHNSCC unfit to TPF. Our results support the design of a study exploring induction by TP for all patients and then after the triple combination of cisplatine, docetaxel and cetuximab.

\section{References}

1. Siegel R, Ma J, Zou Z, Jemal A (2014) Cancer statistics, 2014. CA Cancer J Clin 64: 9-29. [Crossref]

2. Vokes EE, Weichselbaum RR, Lippman SM, Hong WK (1993) Head and neck cancer. N Engl J Med 328: 184-194. [Crossref]

3. Lefebvre JL, Andry G, Chevalier D, Luboinski B, Collette L, et al. (2012) Laryngeal preservation with induction chemotherapy for hypopharyngeal squamous cell carcinoma: 10-year results of EORTC trial 24891. Ann Oncol23: 2708-2714. [Crossref]

4. Cohen EE, Karrison TG, Kocherginsky M, Mueller J, Egan R, et al. (2014) Phase III randomized trial of induction chemotherapy in patients with N2 or N3 locally advanced head and neck cancer. J Clin Oncol 32: 2735-2743. [Crossref]

5. Haddad R, O'Neill A, Rabinowits G, Tishler R, Khuri F, et al. (2013) Induction chemotherapy followed by concurrent chemoradiotherapy (sequential chemoradiotherapy) versus concurrent chemoradiotherapy alone in locally advanced head and neck cancer (PARADIGM): a randomised phase 3 trial. Lancet Oncol 14: 257-264. [Crossref]

6. Hitt R, Grau JJ, López-Pousa A, Berrocal A, García-Girón C, et al. (2014) A randomized phase III trial comparing induction chemotherapy followed by chemoradiotherapy versus chemoradiotherapy alone as treatment of unresectable head and neck cancer. Ann Oncol 25: 216-225. [Crossref]

7. Posner MR, Hershock DM, Blajman CR, Mickiewicz E, Winquist E, et al. (2007) Cisplatin and fluorouracil alone or with docetaxel in head and neck cancer. $N$ Engl $J$ Med357: 1705-1715. [Crossref]

8. Vermorken JB, Remenar E, van Herpen C, Gorlia T, Mesia R, et al. (2007) Cisplatin, fluorouracil, and docetaxel in unresectable head and neck cancer. $N$ Engl J Med357: 1695-1704. [Crossref]

9. Fayette J, Bonnin N, Ferlay C, Lallemant B, Ramade A, et al. (2013) Neoadjuvant TPF in locally advanced head and neck cancer can be followed by radiotherapy combined with cisplatin or cetuximab: a study of 157 patients. Anticancer Drugs 24: 623-629. [Crossref]

10. Pointreau Y, Garaud P, Chapet S, Sire C, Tuchais C, et al. (2009) Randomized trial of induction chemotherapy with cisplatin and 5-fluorouracil with or without docetaxel for larynx preservation. J Natl Cancer Inst 101: 498-506. [Crossref]

11. Lefebvre JL, Rolland F, Tesselaar M, Bardet E, Leemans CR, et al. (2009) Phase 3 randomized trial on larynx preservation comparing sequential vs alternating chemotherapy and radiotherapy. J Natl Cancer Inst 101: 142-152. [Crossref]

12. Forastiere AA, Zhang Q, Weber RS, Maor MH, Goepfert H, et al. (2013) Long-term results of RTOG 91-11: a comparison of three nonsurgical treatment strategies to preserve the larynx in patients with locally advanced larynx cancer. J Clin Oncol 31: 845-852. [Crossref]

13. Blanchard P, Bourhis J, Lacas B, Posner MR, Vermorken JB,et al. (2013) Taxanecisplatin-fluorouracil as induction chemotherapy in locally advanced head and neck cancers: an individual patient data meta-analysis of the meta-analysis of chemotherapy in head and neck cancer group. J Clin Oncol31: 2854-2860. [Crossref]

14. Bonner JA, Harari PM, Giralt J, et al. (2010) Radiotherapy plus cetuximab fo locoregionally advanced head and neck cancer: 5 -year survival data from a phase 3 randomised trial, and relation between cetuximab-induced rash and survival. Lancet Oncol11: 21-28. [Crossref]

15. Vermorken JB, Mesia R, Rivera F, Remenar E, Kawecki A, et al. (2008) Platinumbased chemotherapy plus cetuximab in head and neck cancer. N Engl J Med 359: 11161127. [Crossref]

16. Charalambakis N, Kouloulias V, Vaja H, Pectasides D, Rampias T, et al. (2013) Feasibility of Induction Docetaxel, Cisplatin, 5-Fluorouracil, Cetuximab (TPF-C) Followed by Concurrent Cetuximab Radiotherapy for Locally Advanced Head and Neck Squamous Cell Carcinoma. Front Oncol 3: 5. [Crossref]

17. Guigay J, Fayette J, Dillies AF, et al. (2012) Cetuximab, docetaxel, and cisplatin (TPEx) as first-line treatment in patients with recurrent or metastatic $(\mathrm{R} / \mathrm{M})$ squamous cell carcinoma of the head and neck (SCCHN): Final results of phase II trial GORTEC 2008-03. J Clin Oncol 30.

Copyright: (C2016 Fayette J. This is an open-access article distributed under the terms of the Creative Commons Attribution License, which permits unrestricted use, distribution, and reproduction in any medium, provided the original author and source are credited. 